\title{
Development of Activity of Labour and Occupational Therapies in University Hospital, Pleven, Bulgaria
}

\author{
Vacheva D* \\ Department for Physical Medicine, Bulgaria
}

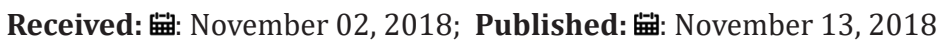

*Corresponding author: Vacheva D, Associate Professor, Department for Physical Medicine, Bulgaria

\begin{abstract}
Object of current article is to share experience of the Clinic of Physical and Rehabilitation Medicine at the University Hospital - Pleven, in the field of labour therapy and occupational therapy as a part of complete rehabilitation of patients suffering various locomotor and mental disorders. The labour therapy and occupational therapy Service at the University Hospital is established in 1965 by the founder of the physiotherapy in the Pleven hospital, Dr. Rusi Risev, MD. A few large premises are furnished and equipped for carpentry shop, spinning and weaving shop, workshop for paper, leather, yarn and threads. The conducted survey, while applying work therapy within a complete rehabilitation program for patients with various traumas and disorders, received results and accumulated clinical experience give us grounds to recommend equipping such premises in hospitals, in wards for physical and rehabilitation medicine, and to state that the work- and occupational therapy shall take its well-deserved place in improving patients' quality of life.
\end{abstract}

Keywords: Labour Therapy; Occupational Therapy; Rehabilitation

\section{Introduction}

Patients appropriate for treatment through work activities are patients with locomotor deficit due to limited scope of movements in separate joints or whole limb, or muscle weakness; disorders of cardio-vascular and respiratory systems; metabolism disorders; psychiatric disorders and problems; children with congenital and acquired disorders of central and peripheral nervous system, locomotor system and post-traumatic conditions.

Labour therapy (LT) is a branch of the physical and rehabilitation medicine and due to its specifics has been established as a separate method of treatment. LT means exercise in the form of work activities with treatment purposes. The significance of LT for restoring patient's independent life and full work capacity is indisputable. The treatment through work activities supports functional, physical and psychic rehabilitation of the patient, improved psychological and emotional state, stimulates patient's desire to participate actively in the rehabilitation process. The fact that the first described treatments through work activities are connected to treatment of psychiatric disorders expressively points out its psychiatric and therapeutic significance.

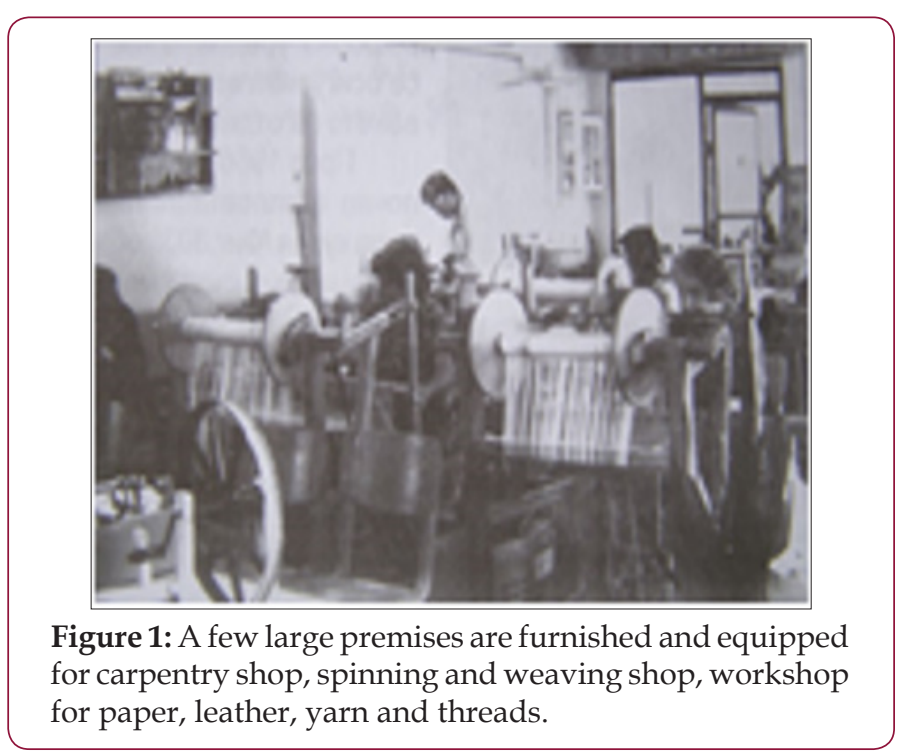

The patient's attention is being kept at the output of the activity which is a basic difference between this therapy and the active kinesiotherapy; it opens chances for emotional expression 
[1]. Occupational therapy deals mainly with everyday life issues of patients with permanent locomotor and psychiatric disorders. Training and re-training for everyday life activities for people with such disorders is of crucial importance for improving and facilitating their life. For each patient the most important matter is self-service - personal hygiene, dressing, feeding, various home activities [2]. Object of current article is to share experience of the Clinic of Physical and Rehabilitation Medicine at the University Hospital - Pleven, in the field of labour therapy and occupational therapy as a part of complete rehabilitation of patients suffering various locomotor and mental disorders. The labour therapy and occupational therapy Service at the University Hospital is established in 1965 by the founder of the physiotherapy in the Pleven hospital, Dr. Rusi Rusev, MD. A few large premises are furnished and equipped for carpentry shop, spinning and weaving shop, workshop for paper, leather, yarn and threads [3] (Figure 1).

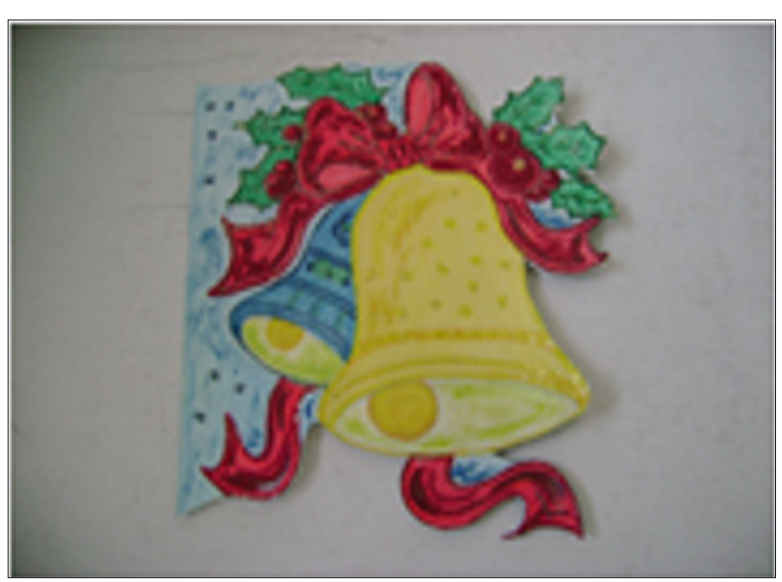

Figure 2: The work with paper includes making cards using the quilling technique, folding paper as in origami, papier mache technique, decoupage technique, cutting and applying decorative elements, weaving items from paper rods and other.

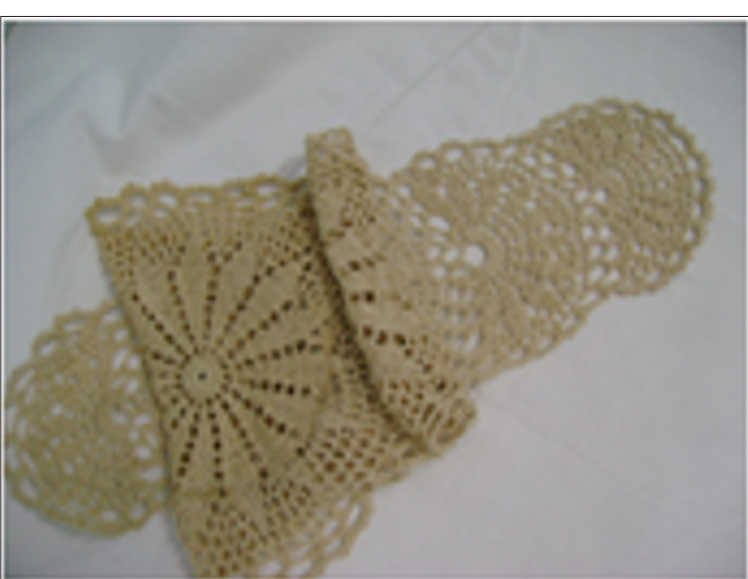

Figure 3: The patients embroider using embroidery frame, tie macramé, apply the ajour technique, weave on horizontals or vertical loom or weaving frame.

In 2004 the Medical University of Pleven opened a new academic specialty - Medical Rehabilitation and Ergotherapy, and therefore expanded and rich work in Labour therapy- Sector is required, in order to conduct seminars and clinical practice for the students. Rehabilitative labour therapy or the so-called functional work therapy has the central place in the Service [1]. Its direct purpose is to influence the locomotor deficit in certain joints, limbs or system. Various activities and work with different materials are very useful [4]. The work with paper includes making cards using the quilling technique, folding paper as in origami, papier mache technique, decoupage technique, cutting and applying decorative elements, weaving items from paper rods and other (Figure 2). When working with yarn and textile materials (yarns, threads, pack-threads, fabric) various items are being knitted or crocheted; the patients embroider using embroidery frame, tie macramé, apply the ajour technique, weave on horizontals or vertical loom or weaving frame (Figure 3). The work with leather includes manufacturing items from leather - glass cases, purses, book clips, book binds and folder binds, jewelry (Figure 4).

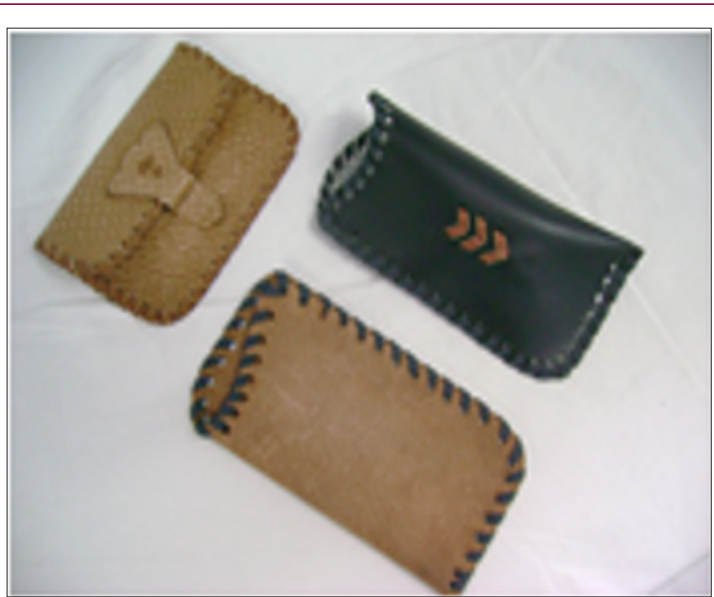

Figure 4: The work with leather includes manufacturing items from leather - glass cases, purses, book clips, book binds and folder binds, jewelry.

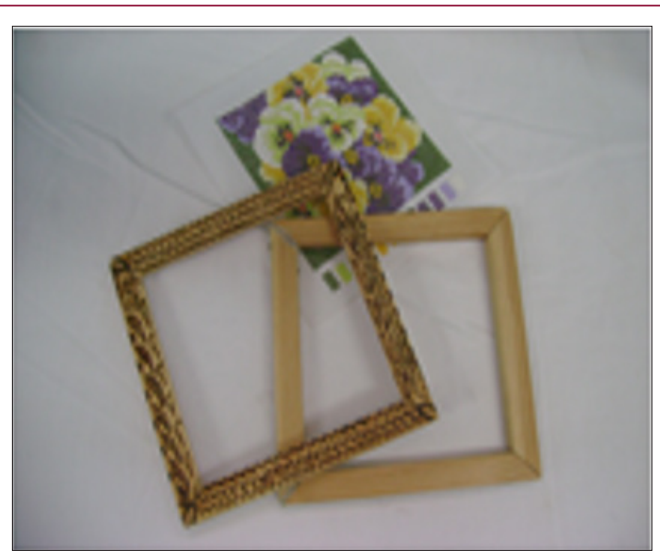

Figure 5: The work with wood includes manufacturing painting frames, fire-writing on souvenirs, processing plywood.

The work with wood includes manufacturing painting frames, fire-writing on souvenirs, processing plywood (Figure 5). When working with plastic materials the easiest to find and use is the bread dough, also fondant dough for making small Figures and 
decoration of confectionary. Available and easy to work with, especially for children, is the plasticine or potter's clay (Figure 6). During the years a work therapy for patients in children age has been developed, called game therapy. It is designated mainly to support the general psychological and physical development of children in certain age and to prevent permanent disability. Various toys are appropriate, to support and improve hand grip, moving objects are used to stimulate initial walking skills, games with imitation; for older children are used various activities from school lessons in Domestic Skills and Techniques and Arts (Figures 7 \& 8).

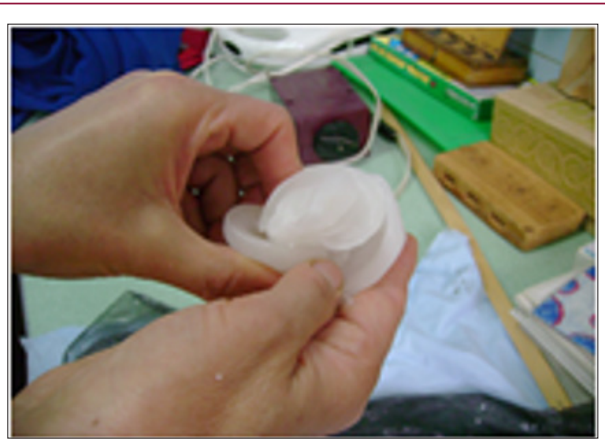

Figure 6: When working with plastic materials the easiest to find and use is the bread dough, also fondant dough for making small figures and decoration of confectionary. Available and easy to work with, especially for children, is the plasticine or potter's clay.

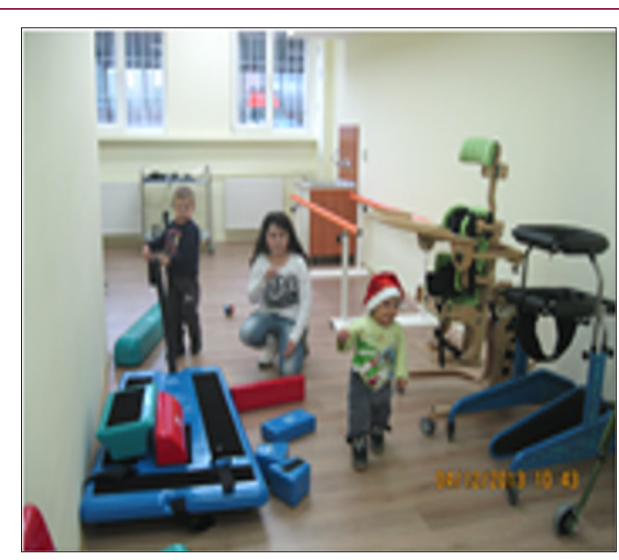

Figure 7: For older children are used various activities from school lessons in Domestic Skills and Techniques and Arts.

ISSN: 2574-1241

DOI: $10.26717 / B J S T R .2018 .11 .002032$

Vacheva D. Biomed J Sci \& Tech Res

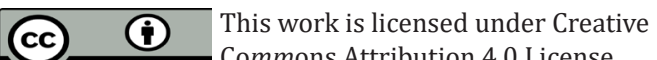

Submission Link: https://biomedres.us/submit-manuscript.php

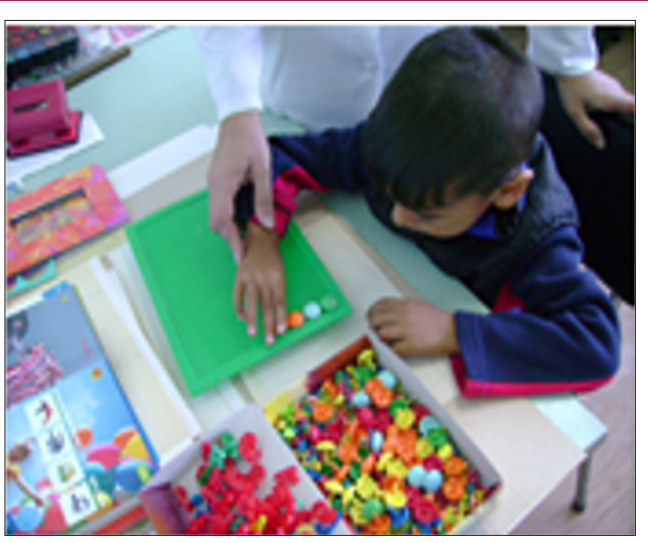

Figure 8: For older children are used various activities from school lessons in Domestic Skills and Techniques and Arts.

\section{Conclusion}

The conducted survey, while applying work therapy within a complete rehabilitation program for patients with various traumas and disorders, received results and accumulated clinical experience give us grounds to recommend equipping such premises in hospitals, in wards for physical and rehabilitation medicine, and to state that the work- and occupational therapy shall take its welldeserved place in improving patients' quality of life. It is our deep belief that we need to popularize work therapy treatment and shall make maximum efforts to restore the activity of abandoned or closed services for work- and occupational therapy or opening new ones, which will contribute to a full-value rehabilitation and independent everyday life of patients.

\section{References}

1. Bankov (1979) Labour therapy. Medicine and Physical Education: Sofia p. 17-20.

2. Topuzov I (2006) Ergotherapy - part I Simel: Sofia p. 10-20.

3. Vacheva D (2007) Creation and development of the "Labor therapy" sector in the Clinic of Physical and Rehabilitation Medicine at the University Hospital in Pleven. Rehabilitation medicine and quality of life (2): 52-54.

4. Matev I, Bankov (1977) Rehabilitation at diseases on hand. Medicine and Physical Education: Sofia pp. 181-184.

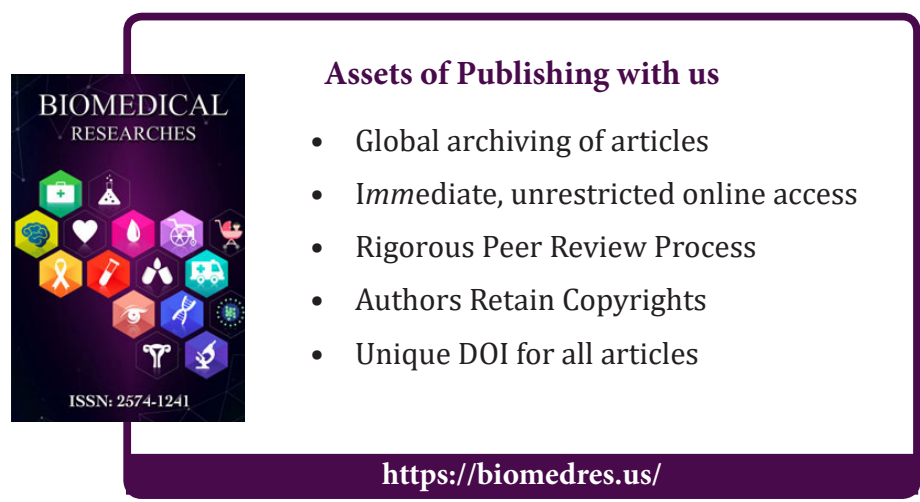

